\title{
Effects of the Rho/Rho-Kinase Pathway on Perfusion Pressure in the Isolated-Perfused Rat Hind Limb Vascular Bed
}

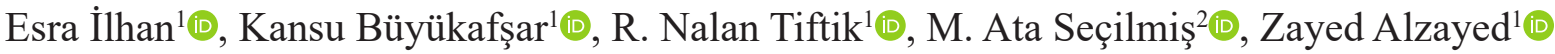

${ }^{1}$ Department of Medical Pharmacology, Mersin University School of Medicine, Mersin, Turkey

${ }^{2}$ Department of Medical Pharmacology, Çukurova University School of Medicine, Adana, Turkey

Background: Rho/ROCK signaling has been demonstrated to be involved in the vascular reactivity of many arterial networks. However, RhoA expression and the contribution of Rho/ROCK pathway to the control of perfusion pressure have not been investigated in the rat hind limb vascular bed as a skeletal muscle vascular network.

Aims: To investigate the contribution of the Rho/ROCK pathway in the control of perfusion pressure in the isolated-perfused rat hind limb vascular bed.

Study Design: Animal experimentation.

Methods: Two Rho inhibitors (atorvastatin and C3 exoenzyme) and ROCK inhibitors (Y-27632 and fasudil) were tested on the phenylephrine-elevated perfusion pressure in the isolated-perfused rat hind limb vascular bed. Furthermore, we sought the expression of RhoA protein in the femoral, popliteal and saphenous arteries as well as quadriceps and gastrocnemius muscles by Western blotting.
Results: The ROCK inhibitors Y-27632 and fasudil (both $10^{-8}$ to $10^{-5} \mathrm{M}$ ) induced substantial vasodilatations. The maximum vasodilatations induced by Y-27632 and fasudil (both at $10^{-5} \mathrm{M}$ ) were $84.0 \pm$ $6.9 \%$ and $76.9 \pm 6.9 \%$, respectively $(P=.091)$. Y-27632 was not more potent than fasudil, as the $\mathrm{EC}_{50}$ values for $\mathrm{Y}-27632$ and fasudil were $0.7 \pm 2.1 \mu \mathrm{M}$ and $2.5 \pm 2.4 \mu \mathrm{M}$, respectively $(P=.177)$. Atorvastatin $\left(10^{-7}\right.$ to $\left.10^{-4} \mathrm{M}\right)$ and $\mathrm{C} 3$ exoenzyme $\left(3 \times 10^{-8} \mathrm{M}\right)$ also produced vasodilatation (maximum vasodilatation; $20.3 \pm 1.7 \%$ and $13.7 \pm 3.6 \%$, respectively). The $\mathrm{EC}_{50}$ value for atorvastatin was $94.9 \pm 1.2 \mu \mathrm{M}$. The western blot analysis showed that the femoral, saphenous, and popliteal arteries, as well as the gastrocnemius and quadriceps muscles, express RhoA protein.

Conclusion: The Rho/ROCK pathway contributes significantly to the control of perfusion pressure in the rat hind limb vascular bed.

\section{INTRODUCTION}

Human skeletal muscle constitutes almost half of the whole body weight and plays a role in the initiation and control of body movements, with substantial impact on cardiovascular homeostasis. ${ }^{1,2}$

Hypertension is associated with many cardiovascular complications, and although there are numerous signaling pathways involved in the pathophysiology, there is no common signaling pathway responsible for the development of the disease.

Rho/ROCK signaling, which mediates calcium-sensitization in vascular smooth muscle, has been demonstrated to play a role in cardiovascular diseases. ${ }^{3}$ Although it has been reported that this pathway could play important roles in the control of perfusion pressure of several vascular beds such as the mesenteric, ${ }^{4}$,
${ }^{5}$ ocular, ${ }^{6}$ pulmonary, ${ }^{7}$ and renal vascular networks, ${ }^{8}$ the role of this signaling has not been investigated in the rat hind limb vascular bed.

The 3-hydroxy-3-methylglutaryl Co enzyme A (HMG$\mathrm{CoA}$ ) reductase inhibitors (statins) are known to inhibit the synthesis of farnesyl pyrophosphate (FPP) and geranylgeranyl pyrophosphate (GGPP), which are recruited for the activation of small GTP-binding Rho proteins. Therefore, they may have the potential to inhibit the activation of the Rho/ROCK signaling. On the other hand, the Clostridium botulinum exoenzyme $\mathrm{C} 3$ has been demonstrated to inactivate RhoA by ADP-ribosylation. ${ }^{9}$ The effects of this toxin on cell migration and membrane raffling were tested in several reports; however, its effects on any isolated arterial segments or on perfusion pressure have yet to be investigated.

Corresponding author: R. Nalan Tiftik, Department of Medical Pharmacology, Mersin University School of Medicine, Mersin, Turkey

e-mail: nalantiftik@yahoo.com

Received: December 4, 2020 Accepted: June 26, 2021 •DOI: 10.5152/balkanmedj.2021.20014

Available at www.balkanmedicaljournal.org

ORCID iDs of the authors: E.İ. 0000-0002-9335-1170; K.B. 0000-0003-4117-6013; R.N.T. 0000-0001-7277-3369; M.A.S. 0000-0002-7224-8764; Z.A. 0000-0002-8178-5377.

Cite this article as:

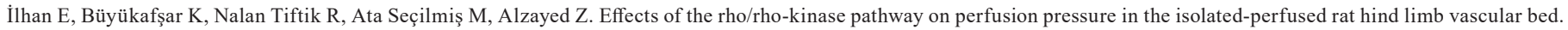
Balkan Med J. 2021;38(5):304-309.

Copyright@Author(s) - Available online at http://balkanmedicaljournal.org/ 
The elevated levels and activity of Rho kinase have been held responsible for hypertension, and have constituted one of the molecular mechanisms of increased arterial pressure. ${ }^{10}$ Therefore, this signaling cascade should be considered as a therapeutic target in the treatment of hypertension and some other related pathologies. $^{3}$

In the isolated-perfused mesenteric arterial network, we previously demonstrated that Rho/Rho-kinase signaling had a substantial influence on the regulation of vascular tone., ${ }^{4}$ Furthermore, this signaling has also been investigated in ocular, ${ }^{6}$ pulmonary, ${ }^{7}$ and renal $^{8}$ circulations. However, the Rho/ROCK pathway has not been investigated yet in any isolated-perfused skeletal muscle vascular beds. Therefore, in this study, we investigated the effects of Rhokinase inhibitors, Y-27632 and fasudil, and also the RhoA inhibitors, Clostridium botulinum exoenzyme C3 and atorvastatin (also an $\mathrm{HMG}-\mathrm{Co} A$ reductase inhibitor) on perfusion pressure in the rat hind limb vascular bed. Furthermore, we sought the expression of RhoA protein in certain arteries and skeletal muscles of the rat hind limb, such as the femoral, popliteal, and saphenous arteries, as well as the quadriceps and gastrocnemius muscles, by western blotting.

\section{MATERIAL AND METHODS}

This study was performed in accordance with the Guide for the Care and Use of Laboratory Animals of Experimental Medicine Unit of the Medical Faculty at Mersin University, and the experimental protocol was approved by the local ethics committee of Mersin University School of Medicine (31/August 22, 2016). Male Wistar albino rats (275-320 g, 3 to 4 months old) were recruited in the study. The rats were killed by a blow to the head and exsanguinated. The abdomen and pelvis were immediately opened. The iliac arteries were traced from the abdominal aorta and one of them was immediately cannulated with a polyethylene cannula. The hind limb vascular bed was then infused with pre-warmed and pre-oxygenated Krebs solution (in millimolar concentration: $\mathrm{KCl}$ 4.7, $\mathrm{NaCl} 118, \mathrm{MgSO}_{4} 1.2, \mathrm{CaCl}_{2} 2.5, \mathrm{KH}_{2} \mathrm{PO}_{4} 1.2, \mathrm{NaHCO}_{3} 25$, $\mathrm{Na}_{2}$ EDTA 0.01, glucose 11) by a heparinized $20 \mathrm{~mL}$ injector. The hind limb was disconnected from the hip conjunction, and the foot, leg, and hip were removed as a whole. This cannulated hind limb was transferred to a jacketed Plexiglas cradle, which was continuously kept warm at $37^{\circ} \mathrm{C}$ by use of a heating circulator. The vascular bed of the hind limb was perfused with Krebs solution (aerated with $95 \% \mathrm{O}_{2}$ and $5 \% \mathrm{CO}_{2}$ ) at a fixed flow rate of $5.5 \mathrm{~mL} / \mathrm{min}$ with a peristaltic pump (Peri-Star, WPI, Berlin, Germany). In order to check endothelial integrity, acetylcholine $(0.01$ and $0.1 \mu \mathrm{g})$ was injected into the perfusate in the silicon rubber close to the vascular bed, at a volume of $100 \mu \mathrm{L}$.

The ROCK inhibitors Y-27632 and fasudil, or the RhoA inhibitors $\mathrm{C} 3$ and atorvastatin, were added to a scaled reservoir that was maintained at $37^{\circ} \mathrm{C}$ and gassed with $95 \% \mathrm{O}_{2}$ and $5 \% \mathrm{CO}_{2}$ continuously, and from which the Krebs solution was continuously perfused to the hind limb vascular bed. The perfusion pressure of the hind limb vascular bed was continuously measured with a pressure transducer (COMMAT, Ankara/Turkey) and recorded on a Biopac acquisition system (BIOPAC Systems, California, USA). Once we had observed that removal of the skin could enable us to obtain a stable perfusion pressure, we wiped-off the skin covering the hind limb in every experiment, in a procedure similar to the removal of renal and eye capsules. ${ }^{8}$ This prevented the uncontrolled rise in the perfusion pressure.

After equilibration of 30-40 minutes, the perfusion pressure of the hind limb vascular bed was increased by using $10^{-6} \mathrm{M}$ phenylephrine to induce a submaximal vasoconstrictor response. Following a steady-state increase in perfusion pressure, the ROCK inhibitors, Y-27632 or fasudil (both $10^{-8}$ to $10^{-5} \mathrm{M}$ ), or the RhoA inhibitors C3 $\left(3 \times 10^{-8} \mathrm{M}\right)$ and atorvastatin $\left(10^{-7}\right.$ to $\left.10^{-4} \mathrm{M}\right)$, were cumulatively added to the reservoir to allow a maximum decrease in perfusion pressure for all concentrations.

In one of the experimental series, saponin was perfused at a $50 \mathrm{mg} / \mathrm{mL}$ concentration for 5 minutes to remove the endothelial lining. The integrity of the endothelium was checked by 0.01 and $0.1 \mu \mathrm{g}$ acetylcholine injected at a volume of $100 \mu \mathrm{L}$ into the silicone rubber through which the perfusing solution flowed in.

\section{Western Blotting for RhoA}

The femoral, popliteal, and saphenous arteries and the quadriceps and gastrocnemius muscles were isolated carefully and immediately, and western blotting was performed according to the method described previously by Büyükafşar et al. ${ }^{11}$ A primary antibody was raised against RhoA (Thermo Fisher Scientific USA or Santa Cruz Biotechnology, CA, USA) at $1: 1000$ dilution, followed by a horseradish peroxidase-conjugated secondary antibody (1:1000, Santa Cruz Biotechnology). The ECL Advance Western Blotting Detection Kit (Amersham Biosciences) was used for the detection of the blots.

\section{Drugs and Chemicals}

Acetylcholine chloride and phenylephrine hydrochloride were purchased from Sigma (St. Louis, MO, USA), and C3 from Fluka (Deisenhofen, Germany). Fasudil and Y-27632 were obtained from Tocris Cookson (Bristol, UK). Atorvastatin was generously gifted by Eczacıbaşı Pharmaceutical and Industrial Investment Co (İstanbul, Turkey). Atorvastatin and C3 were dissolved in DMSO and Krebs solution, respectively. All other chemicals were dissolved in distilled water. Solvent control for all series was performed.

\section{Data Analysis}

The decrease in perfusion pressure induced by the Rho and ROCK inhibitors and acetylcholine is expressed as percentage reduction of phenylephrine-induced vasoconstriction, and shown as mean $\pm \mathrm{SD}$. The normality distribution of all data was checked in the GraphPad prism program with the Shapiro-Wilk test. For statistical evaluation, the Kruskal-Wallis test followed by the DunnBonferroni method for the pairwise comparisons were used, and the Student's $t$-test was used when appropriate. Values of $P<.05$ were considered as significant. The Prism GraphPad Version 3.0 
was used to calculate the $\mathrm{EC}_{50}$ value. The $\mathrm{EC}_{50}$ value is the concentration at which the inhibitor compounds (i.e., the Rho and ROCK inhibitors) exert half of their maximal vasodilator responses, and is expressed as a micromolar concentration. The sample size was determined with the "resource equation" method (MEAD), which is a frequently used method in animal experiments. ${ }^{12}$

\section{RESULTS}

Effects of the ROCK Inhibitors Y-27632 and Fasudil on Perfusion Pressure of the Rat Hind Limb Vascular Bed The ROCK inhibitors, Y-27632 and fasudil, induced marked vasodilatory responses in a dose-dependent manner in the isolatedperfused rat hind limb vascular bed, the perfusion pressure of which was elevated by an $\alpha$-adrenoceptor agonist, phenylephrine (Figure 1A and B). Y-27632 was not more potent than fasudil, as there was no statistically significant difference between their $\mathrm{EC}_{50}$ values, which were $0.7 \pm 2.1 \mu \mathrm{M}$ for $\mathrm{Y}-27632$ and $2.5 \pm 2.4 \mu \mathrm{M}$ for fasudil $(P=.177)$. The Emax values for both $\mathrm{Y}-27632$ and fasudil were also $84.0 \pm 6.9 \%$ and $76.9 \pm 6.9 \%$, respectively $(P=.091)$ (Table 1$)$.

\section{Effects of Endothelium Removal by Saponin on the} Vasodilatation Induced by Y-27632 and Fasudil

Saponin perfusion ( $50 \mathrm{mg} / \mathrm{mL}$ for 5 minutes) successfully removed the endothelial lining, as it almost abolished the vasodilator responses to acetylcholine, which evoked $16.8 \pm 3.5 \%$ and 50.2 $\pm 7.5 \%$ vasodilatation at $0.01 \mu \mathrm{g}$ and $0.1 \mu \mathrm{g}$, respectively. However, the corresponding vasodilator responses were $1.1 \pm 0.8 \%$ $(P<.001)$ and $3.0 \pm 2.2 \%(P<.001)$ after saponin perfusion (Figure 1C). After successful removal of the endothelium from the hind limb vasculature by saponin, the vasodilator responses to the ROCK inhibitors were not significantly different from control (Figure 1A and B). The $P$ values for the Kruskal-Wallis test were $P<.0001$ for both data in Figure 1A and B, but the results for the Dunn-Bonferroni test for the pairwise comparisons were not significant $(P>.050$ for all group comparisons). In the saponin groups, the $\mathrm{EC}_{50}$ values were $1.3 \pm 1.7 \mu \mathrm{M}$ for $\mathrm{Y}-27632$ and $1.0 \pm$ $1.0 \mu \mathrm{M}$ for fasudil $(P=.810)$, while the $\mathrm{E}_{\max }$ values were $77.8 \pm$ 12.7 and $72.2 \pm 28.4(P=.710)$, respectively. The $\mathrm{E}_{\max }$ and $\mathrm{EC}_{50}$ values of the ROCK inhibitors are shown in Table 1.

\section{Effects of C3 and Atorvastatin (Rho Inhibitors) on Perfusion Pressure of the Rat Hind Limb Vascular Bed}

The Rho inhibitors C3 and atorvastatin elicited mild-to-moderate vasodilator activity. In our experimental set-up, we only tested 3 $\times 10^{-8}$ м C3, and at this concentration, the toxin induced a slight decrease in perfusion pressure $(13.7 \pm 3.6 \%)$. However, the RhoA as well as HMG-CoA reductase inhibitor atorvastatin evoked a moderate vasodilator response, being the $\mathrm{EC}_{50}$ value, $94.9 \pm 1.2$ $\mu \mathrm{M}$ (Figure 2). Since atorvastatin and $\mathrm{C} 3$ did not elicit a substantial
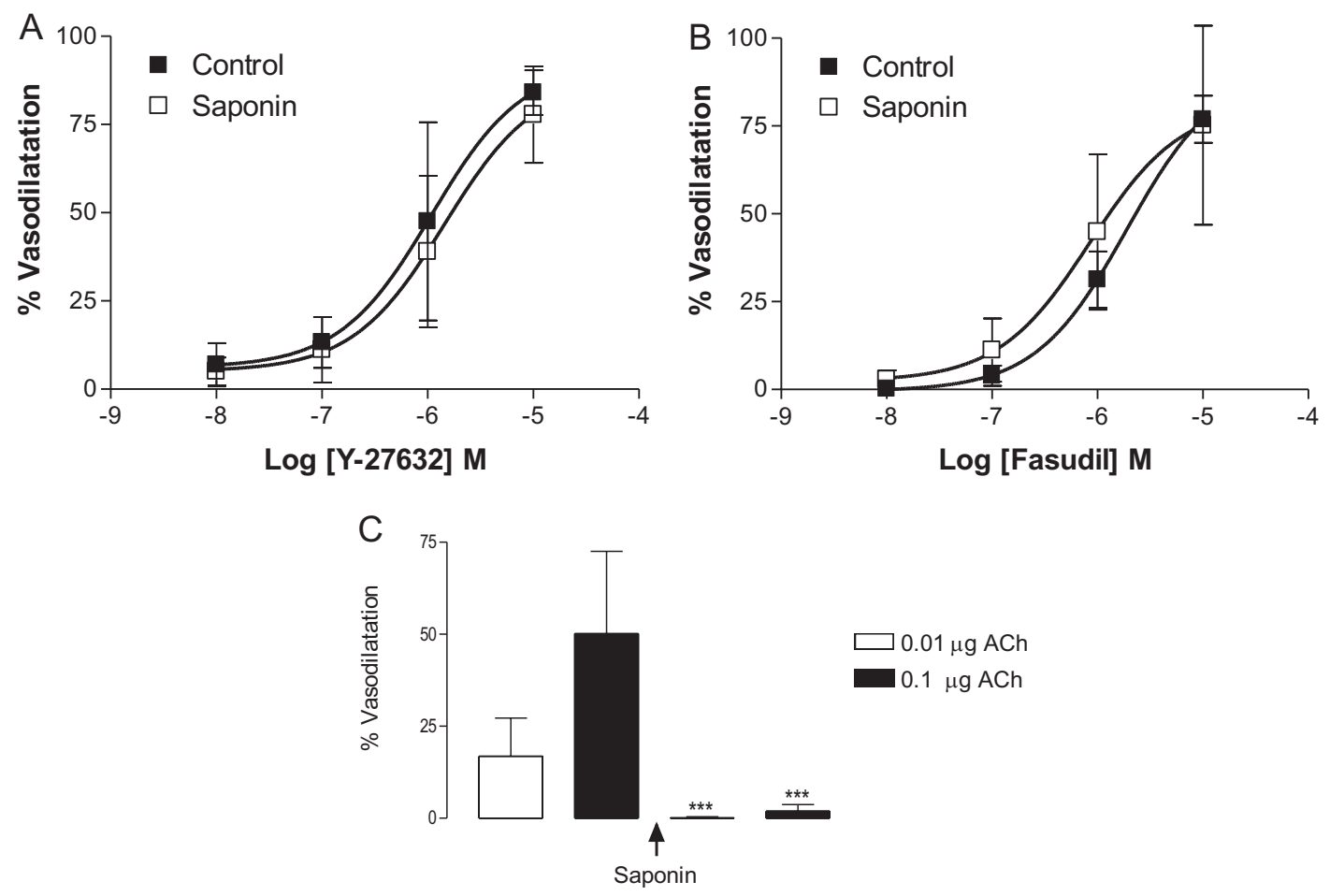

FIG. 1. A-C. Effects of the ROCK inhibitors Y-27632 $\left(10^{-8}\right.$ to $10^{-5} \mathrm{M}$, cumulatively, $n=7$ (A), and fasudil $\left(10^{-8}\right.$ to $10^{-5} \mathrm{M}$, cumulatively, $n=4$ (B), in the absence and presence of saponin $(50 \mathrm{mg} / \mathrm{mL}, 5 \mathrm{~min})$ on the perfusion pressure in the isolated-perfused rat hind limb vascular bed, the perfusion pressure of which was elevated by phenylephrine, an $\alpha$-adrenergic receptor agonist. The effect of saponin ( $50 \mathrm{mg} / \mathrm{mL}, 5 \mathrm{~min}$ ) (C) on acetylcholine-induced (0.01 and $0.1 \mu \mathrm{g}$, bolus) vasodilation was tested to check the endothelial integrity. Data were expressed as mean \pm SD for $n$ observation. Statistical analysis was performed with the Kruskal-Wallis test followed by the Dunn-Bonferroni method for the pairwise comparisons for data expressed in Figure 1A and B, and the Student's $t$-test for Figure 1C. "' $P<.001$. 
TABLE 1. Demonstration of $\mathrm{EC}_{50}$ and $\mathrm{E}_{\max }$ Values of the ROCK Inhibitors, Y-27632, and Fasudil, in the Absence or Presence of Saponin (50mg/mL, 5 min)

\begin{tabular}{|c|c|c|c|c|c|c|}
\hline & \multicolumn{3}{|c|}{$\mathrm{EC}_{50}$ Values } & \multicolumn{3}{|c|}{$\mathrm{E}_{\max }$} \\
\hline & Control & Saponin & $P$ & Control & Saponin & $P$ \\
\hline Y-27632 & $0.7 \pm 2.1 \mathrm{M}, n=7$ & $1.3 \pm 1.7 \mathrm{M}, n=7$ & $.330^{\mathrm{a}}$ & $84.0 \pm 6.9, n=7$ & $77.8 \pm 12.7, n=7$ & $.085^{\mathrm{c}}$ \\
\hline Fasudil & $2.5 \pm 2.4 \mathrm{M}, n=6$ & $1.0 \pm 1.0 \mathrm{M}, n=4$ & $.090^{\mathrm{b}}$ & $76.9 \pm 6.9, n=6$ & $72.2 \pm 28.4, n=4$ & $.700^{\mathrm{d}}$ \\
\hline$P$ & $.177^{\mathrm{e}}$ & $.810^{\mathrm{f}}$ & & $.091^{\mathrm{g}}$ & $.710^{\mathrm{h}}$ & \\
\hline
\end{tabular}

Data were expressed as mean \pm SD Student's $t$-test was used for statistical comparison. No significance observed between the control and saponin groups.

${ }^{\mathrm{a}}$ Control versus saponin, in theY-27632 group for $\mathrm{EC}_{50}$.

${ }^{\mathrm{b}} \mathrm{Control}$ versus saponin, in the fasudil group for $\mathrm{EC}_{50}$.

${ }^{c}$ Control versus saponin, in the $\mathrm{Y}-27632$ group for $\mathrm{E}_{\max }$

${ }^{\mathrm{d}}$ Control versus saponin, in the fasudil group for $\mathrm{E}_{\max }$.

eY-27632 versus fasudil, in the control group for $\mathrm{EC}_{50}$

${ }^{\mathrm{f}} \mathrm{Y}-27632$ versus fasudil, in the saponin group for $\mathrm{EC}_{5}$.

${ }^{g} \mathrm{Y}-27632$ versus fasudil, in the control group for $\mathrm{E}_{\max }$

${ }^{\text {h}} Y-27632$ versus fasudil, in the saponin group for $\mathrm{E}_{\max }$.

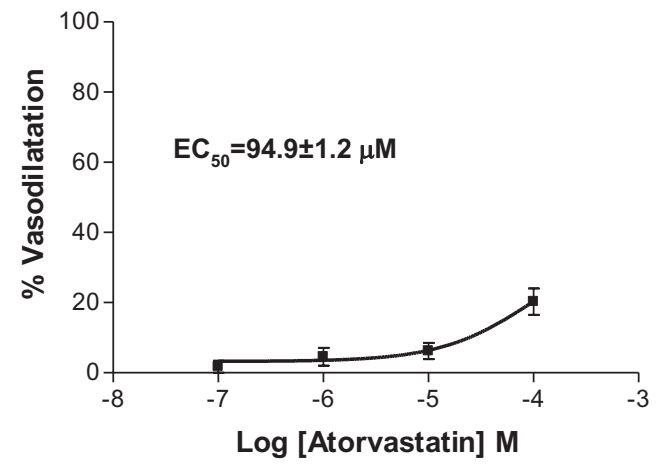

FIG. 2. Vasodilator responses to atorvastatin $\left(10^{-7}\right.$ to $\left.10^{-4} \mathrm{M}, n=6\right)$, and RhoA as well as HMG-CoA-reductase inhibitor on perfusion pressure in the isolated-perfused rat hind limb vascular bed, the perfusion pressure of which was elevated by phenylephrine, an $\alpha$-adrenergic receptor agonist. Data are expressed as mean \pm SD for 6 observations. vasorelaxation, experiments requiring endothelium removal were not performed.

\section{Expression of RhoA in the Rat Hind Limb Vasculature and Skeletal Muscles}

The western blot analysis showed that RhoA is expressed in the femoral, popliteal, and saphenous arteries. Furthermore, these proteins were also expressed in the tissues of the quadriceps and gastrocnemius muscles (Figure 3).

\section{DISCUSSION}

In this study, we tested 2 specific ROCK inhibitors, Y-27632 and fasudil, as well as the RhoA inhibitors, C3 and atorvastatin (also an HMG-CoA reductase inhibitor) on the control of perfusion pressure in the isolated-perfused rat hind limb vascular bed. Moreover, we investigated the expression of RhoA in the femoral, saphenous, and popliteal arteries and in the gastrocnemius and quadriceps muscles.

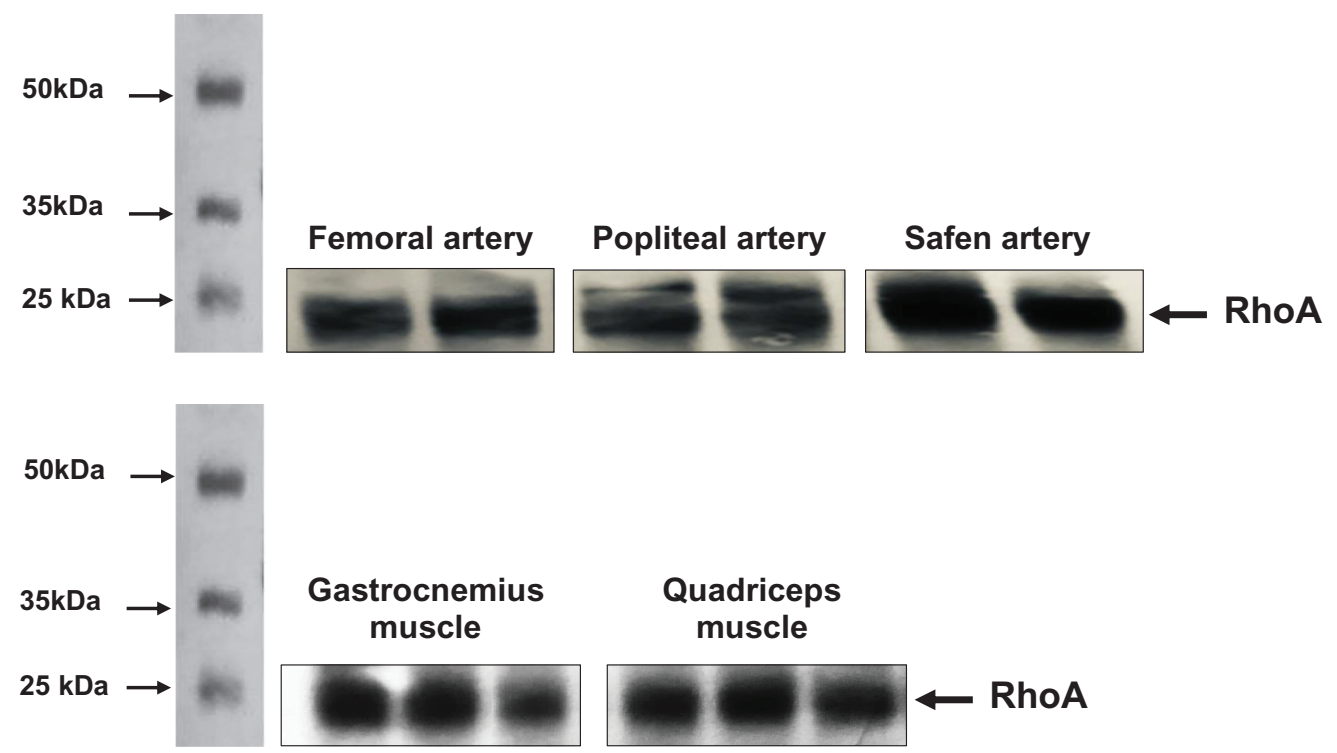

FIG. 3. Demonstration of RhoA expression in the femoral $(n=6)$, popliteal $(n=4)$, and saphenous $(n=3)$ arteries (upper panel), as well as the gastrocnemius $(n=6)$ and quadriceps $(n=6)$ muscles (lower panel) by Western blotting. The right columns show the molecular weights at which the RhoA protein has been demonstrated, at around $21-24 \mathrm{kDa}$. 
We demonstrated that ROCK inhibitors can substantially induce a decrease in the perfusion pressure, which was increased by phenylephrine, an ${ }_{1}$-agonist that has been reported to be coupled with Rho/ROCK signaling to induce vascular constriction. ${ }^{5}$ The vasodilator responses to the ROCK inhibitors were shown to be independent of the functional endothelium. Consistent with this data, in the rat tail small artery ${ }^{13}$ and mesenteric arterial bed, ${ }^{4}$ the vasodilator responses to ROCK inhibitors were not modified by endothelium removal.

There were no differences between the ROCK inhibitors, in either the maximum vasodilation response or potency. However, we previously demonstrated that Y-27632 was more potent than fasudil in relaxing the arterial network such as the mesenteric vascular bed. ${ }^{4}$ This may be due to the difference in the arterial network. In general, the vasodilator effects of ROCK inhibitors have been explored in isolated arterial segments. However, it has been reported that the microvascular network (i.e., resistance arteries) is a better fit to study the effects of vasodilator drugs on hypertension, ${ }^{4}$ Thus, in this study, we sought the vasodilator characteristics of the inhibitors of RhoA and ROCK in the skeletal muscle vascular bed.

On the other hand, atorvastatin could also produce a moderate vasodilator response. The vasodilator effect of atorvastatin is in agreement with the report by Uydeş-Doğan et al. ${ }^{15}$ Atorvastatininduced vasodilatation was reported to be dependent on the functional endothelium releasing nitric oxide (NO). However, we did not check the endothelium dependence as it produces mild-to-moderate vasodilator activity.

Moreover, atorvastatin has pleiotropic effects that are attributed to the inhibition of isoprenoids such as FPP and GGPP in the mevalonate pathway, thereby inhibiting Rho protein activation. Thus, inhibiting the Rho/ROCK pathway due to Rho protein inactivation, atorvastatin inhibits vascular smooth-muscle contraction. ${ }^{16}$ Furthermore, statins have also been reported to scavenge superoxide anions. ${ }^{17-19}$

Another RhoA inhibitor, the C. botulinum exoenzyme C3, induced a slight vasodilator response at the concentration we used $\left(3 \times 10^{-8} \mathrm{M}\right)$. However, we could not increase the concentration of $\mathrm{C} 3$ in our perfusion set-up, and therefore we were unable to establish a dose-response curve, because it would take a massive amount of $\mathrm{C} 3$ in the continuously perfusing system which we could not afford. As far as we are concerned, the vasodilator effect of C3 was tested for the first time in a vascular networkan isolated-perfused rat hind limb vascular bed. The rapid onset of action of $\mathrm{C} 3$ as shown in this study may be explained by the rapid ADP-ribosylation of RhoA proteins with the toxin or by any other mechanism. In support, an injection of botulinum toxin to rats and mice resulted in the effects, which began within minutes. ${ }^{20}$ The $\mathrm{C} 3$ exoenzyme does not have access to the intact cell, as no specific mechanism for the internalization of $\mathrm{C} 3$ exoenzyme has been demonstrated. However, some proteins, like vimentin, have been identified as membranous C3-binding partners involved in the binding and uptake of $\mathrm{C} 3 .{ }^{21}$ We do not know whether such a mechanism exists in this vascular tissue. Despite up to $3 \times 10^{-8} \mathrm{M}$ concentration, we achieved only a slight vasodilatation with $\mathrm{C} 3$, if any, in the hind limb vascular bed, implying the weak internalization of the toxin and/or a short exposure time.

In this study, we also demonstrated that rat quadriceps and gastrocnemius muscles, as well as the femoral, popliteal, and saphenous arteries, express RhoA protein. In numerous reports, the expression of Rho proteins was shown in several types of arteries. On the other hand, the RhoA protein is present in skeletal muscles. ${ }^{22}$

The human skeletal muscle mass is a huge organ constituting around $40-45 \%$ of our body mass and is supplied with a dense arterial vascular network. Especially during exercise, it takes a massive amount of blood from the circulation. Therefore, it appears that human skeletal muscles could fundamentally affect cardiovascular physiology. Accordingly, post-exercise hypotension could occur after a bout of exercise, with alterations in cardiac output and vascular resistance. ${ }^{2}$ Thus, the vasodilator characteristics of the ROCK inhibitors are of pharmacological importance in the skeletal muscle vascular bed. In vivo studies in which vasodilator responses to ROCK inhibitors during exercising are evaluated, need to be performed.

In conclusion, our findings clearly demonstrate that the Rho/ ROCK signaling pathway could contribute to the control of perfusion pressure in the rat hind limb vascular bed. We could also propose that the isolated-perfused rat hind limb preparation may be used to explore the effects of any agents on the vascular network, as it involves not only the capacitance arteries but also the small resistance arteries, together with a huge muscle mass.

A part of this article was orally presented in the "Sixth International Multidisciplinary Studies Congress/April 26-27, 2019, Gaziantep, Turkey.

Ethics Committee Approval: The experimental protocol of the study was approved by the Ethical Committee for Experimental Animals of Mersin University, and all efforts were made to minimize the number of animals used (Ethics Approval Number/Date: 31/August 22, 2016)

Patient Consent for Publication: N/A.

Data-sharing Statement: Authors elect not to share data.

Author Contributions: Concept - K.B.; Design - K.B., M.A.S.; Supervision - M.A.S.; Resources - K.B.; Data Collection and/or Processing - E.İ., K.B., R.N.T., M.A.S., Z.A.; Analysis and/or Interpretation - E.I., K.B., R.N.T., M.A.S., Z.A.; Literature Review - E.İ., K.B., R.N.T., M.A.S., Z.A.; Writing - E.İ., K.B., R.N.T., M.A.S., Z.A.; Critical Review E.I., K.B., R.N.T., M.A.S., Z.A.

Acknowledgments: The authors are indebted to M Saeed Attar and Khairat Al Hennawi for their help with western blotting.

Conflict of Interest: The authors have no conflicts of interest to declare.

Funding: This study was supported by Mersin University Research Project Unit (2018-2-AP3-2938). 


\section{REFERENCES}

1. Shenkman BS, Turtikova OV, Nemirovskaya TL, Grigoriev AI. Skeletal muscle activity and the fate of myonuclei. Acta Nat. 2010;2(2):59-66. [CrossRef]

2. MacDonald JR. Potential causes, mechanisms, and implications of post exercise hypotension. J Hum Hypertens. 2002;16(4):225-236. [CrossRef]

3. Mukai Y, Shimokawa H, Matoba T, et al. Involvement of Rho-kinase in hypertensive vascular disease: a novel therapeutic target in hypertension. FASEB J. 2001;15(6):1062-1064. [CrossRef]

4. Büyükafşar K, Arikan O, Ark M, et al. Rho-kinase expression and its contribution to the control of perfusion pressure in the isolated rat mesenteric vascular bed. Eur $J$ Pharmacol. 2004a;485(1-3):263-268. [CrossRef]

5. Büyükafşar K, Arikan O, Ark M, Kubat H, Ozveren E. Upregulation of Rho-kinase (ROCK-2) expression and enhanced contraction to endothelin-1 in the mesenteric artery from lipopolysaccharide-treated rats. Eur $J$ Pharmacol. 2004b;498(1-3):211-217. [CrossRef]

6. Pattabiraman PP, Inoue T, Rao PV. Elevated intraocular pressure induces Rho GTPase mediated contractile signaling in the trabecular meshwork. Exp Eye Res. 2015;136:29-33. [CrossRef]

7. Krauszman A, Mak TW, Szaszi K, Kuebler WM. Role of phosphatase and tensin homolog in hypoxic pulmonary vasoconstriction. Cardiovasc Res. 2017;113(8):869-878. [CrossRef]

8. Kurt AH, Büyükafşar K. Vasoconstriction induced by G1, a G-protein-coupled oestrogen receptor1 (GPER-1) agonist, in the isolated perfused rat kidney. Eur J Pharmacol. 2013;702(1-3):71-78. [CrossRef]

9. Woodside DG, Wooten DK, McIntyre BW. Adenosine diphosphate (ADP)-ribosylation of the guanosine triphosphatase (GTPase) rho in resting peripheral blood human $\mathrm{T}$ lymphocytes results in pseudopodial extension and the inhibition of $\mathrm{T}$ cell activation. J Exp Med. 1998;188(7):1211-1221. [CrossRef]

10. Shimokawa H, Sunamura S, Satoh K. RhoA/rho-kinase in the cardiovascular system. Circ Res. 2016;118(2):352-366. [CrossRef]

11. Büyükafşar K, Yalçin I, Kurt AH, et al. Rho-kinase inhibitor, Y-27632, has an antinociceptive effect in mice. Eur J Pharmacol. 2006;541(1-2):49-52. [CrossRef]
12. Festing MF. On determining sample size in experiments involving laboratory animals Lab Anim. 2018;52(4):341-350. [CrossRef]

13. Schubert R, Kalentchuk VU, Krien U. Rho kinase inhibition partly weakens myogenic reactivity in rat small arteries by changing calcium sensitivity. Am J Physiol Heart Circ Physiol. 2002;283(6):H2288-H2295. [CrossRef]

14. D'Orléans-Juste P, Berthiaume N, Plante GE, Bkaily G, Claing A. Comparison of the pre- and post-capillary vascular reactivity in the rat and guinea pig perfused mesenteric bed. Can J Physiol Pharmacol. 1996;74(7):811-817. [CrossRef]

15. Sönmez Uydeş-Doğan B, Topal G, Takir S, et al. Relaxant effects of pravastatin, atorvastatin and cerivastatin on isolated rat aortic rings. Life Sci. 2005;76(15):1771-1786. [CrossRef]

16. Wang CY, Liu PY, Liao JK. Pleiotropic effects of statin therapy: molecular mechanisms and clinical results. Trends Mol Med. 2008;14(1):37-44. [CrossRef]

17. Kaesemeyer WH, Caldwell RB, Huang J, Caldwell RW. Pravastatin sodium activates endothelial nitric oxide synthase independent of its cholesterol-lowering actions. $J$ Am Coll Cardiol. 1999;33(1):234-241. [CrossRef]

18. Wagner AH, Köhler T, Rückschloss U, Just I, Hecker M. Improvement of nitric oxide-dependent vasodilatation by HMG-CoA Reductase Inhibitors through attenuation of endothelial superoxide anion formation. Arterioscler Thromb Vasc Biol. 2000;20(1):61-69. [CrossRef]

19. Lefer DJ, Scalia R, Jones SP, et al. HMG-CoA reductase inhibition protects the diabetic myocardium from ischemia-reperfusion injury. FASEB J. 2001;15(8):1454-1456. [CrossRef]

20. Ravichandran E, Gong Y, Al Saleem FH, et al. An initial assessment of the systemic pharmacokinetics of botulinum toxin. JPharmacol Exp Ther. 2006;318(3):1343-1351. [CrossRef]

21. Rohrbeck A, Just I. Cell entry of C3 exoenzyme from Clostridium botulinum. Curr Top Microbiol Immunol. 2017;406:97-118. [CrossRef]

22. Sar1 AN, Kacan M, Unsal D, et al. Contribution of RhoA/Rho-kinase/MEK1/ERK1/2/ iNOS pathway to ischemia/reperfusion-induced oxidative/nitrosative stress and inflammation leading to distant and target organ injury in rats. Eur J Pharmacol. 2014;723:234-245. [CrossRef] 